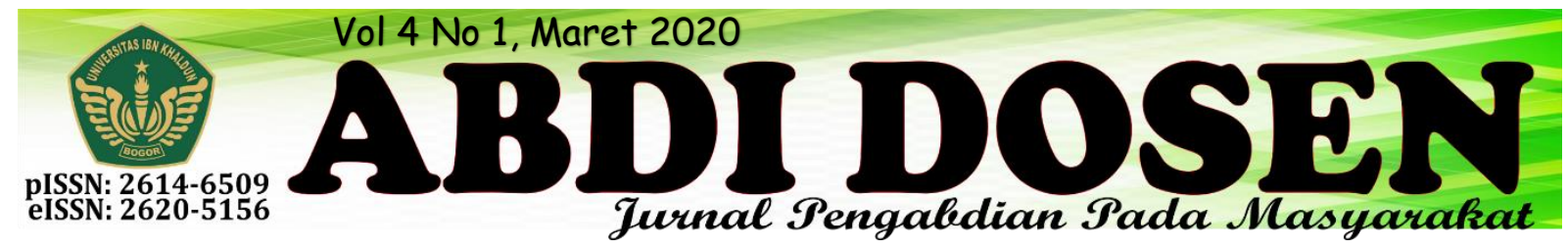

\title{
PEMBANGUNAN TAMAN BACA MASYARAKAT DI RW O3 DESA KALONG 1 UNTUK MENINGKATKAN MINAT BACA MASYARAKAT
}

\author{
Santi Lisnawati ${ }^{1}$, Ritzkal $^{2}$, Shania Meiriestiani $^{3}$ \\ santilisnawati@gmail.com ${ }^{1}$ \\ ritzkal@ft.uika-bogor.ac.id ${ }^{2}$
}

Dosen Fakultas Agama Islam¹, Dosen Fakultas Teknik dan Sains², Mahasiswa KKN Kelompok 37\&38 Tahun $2019^{3}$

\begin{abstract}
ABSTRAK
Kuliah kerja nyata merupakan salah satu kegiatan untuk syarat wisuda setiap mahasiswa di Universitas Ibn Khaldun Bogor. Selama kurang lebih 30 hari, mahasiswa melakukan pendekatan dengan masyarakat dan merencakan program-program kerja di Desa Kalong I Kecamatan Leuwisadeng. Masyarakat di Desa Kalong I merupakan masyarakat yang beragam (heterogen) sehingga program-program kerja disesuaikan dengan kondisi dan potensi yang ada. Pendidikan, teknologi, kesehatan, dan ekonomi merupakah salah satu faktor penting yang dapat mempengaruhi kehidupan masyarakat Desa Kalong I. Sebanyak 16\% masyarakat Desa Kalong I masih mengemban dunia Pendidikan dan sisanya merupakan masyarakat dewasa yang berdagang. Namun, minimnya fasilitas yang memadai untuk meningkatkan pengetahuan mereka, membuat mereka kurang mendapat literasi terhadap pentingnya membaca, mempelajari ekonomi perdagangan, ilmu kesehatan, dan teknologi. Pembangunan Taman Baca Masyarakat (TBM) ini merupakan salah satu pendekatan yang dapat meningkatkan multi disiplin di masyarakat. Pada TBM ini, tersedia buku-buku dari berbagai bidang seperti bidang agama, pendidikan, ekonomi, dan pengetahuan umum.
\end{abstract}

\section{Kata Kunci: Pendidikan, Ekonomi, Kesehatan, Teknologi, Baca, Literasi, Potensi}

\section{PENDAHULUAN}

Berdasarkan hasil observasi kelompok KKN 37 dan 38 didapati permasalahan di Desa Kalong I. Permasalahan tersebut adalah kurangnya literasi terhadap pentingnya membaca, mempelajari ekonomi perdagangan, ilmu kesehatan, dan teknologi. Menurut Santoso (2008) "membaca merupakan kegiatan dan kemampuan khas manusia". Sehingga kemampuan ini perlu ditingkatkan agar bisa membuat manusia lebih berkualitas.

Kemampuan ini membutuhkan minat yang hadir dari sendiri. Kepeduliaan terhadap membaca penting adanya agar pengetahuan masyarakat meningkat. Namun, hadirnya teknologi terkadang menjadi faktor yang mempengaruhi kepeduliaan masyarakat untuk membaca dan membuat masyarakat lebih senang mengakses internet daripada membaca buku.

Kondisi ini diperburuk dengan minimnya fasilitas yang memadai untuk kegiatan membaca masyarakat di Desa Kalong I. Fasilitas yang terdiri dari ketersediaan buku-buku dari berbagai bidang seperti bidang agama, pendidikan, 
ekonomi, dan pengetahuan umum sangat penting keberadaannya.

Masyarakat sebanyak 16\% di Desa Kalong I masih mengemban dunia pendidikan. Namun, masih banyak masyarakat yang kurang melek terhadap pentingnya membaca. Sangat perlu adanya pembinaan terhadap membaca, sehingga masyarakat dapat meningkatnya daya minatnya. Upaya yang dapat dilakukan adalah dengan adanya pembuatan Taman Baca Masyarakat (TBM). Tujuannya adalah selain menyediakan buku-buku untuk masyarakat membaca, juga membantu meningkatkan daya minat membacanya.

\section{Geografis}

Desa Kalong I merupakan bagian dari Kecamatan Leuwisadeng, Kabupaten Bogor, Provinsi Jawa Barat. Secara umum keadaan geografis Desa Kalong I merupakan daerah dengan total luas tanah 344,60 Ha,terdiri atas tanah sawah seluas 123,30 Ha dengan rincian 63,60 Ha sawah irigasi $1 / 2$ teknis, 32,20 Ha sawah tadah hujan 27,50 Ha sawah pasang surut. Selain itu terdapat pula tanah kering seluas 213,10 Ha dengan rincian 160,20 Ha tegal/lading, 37,40 Ha pemukiman, dan 15,50 Ha pekarangan. Kelompok KKN 37 dan 38 ditempatkan di RW 03 Kampung Pabuara Tonggoh, Desa Kalong I.

\section{Peta Lokasi}

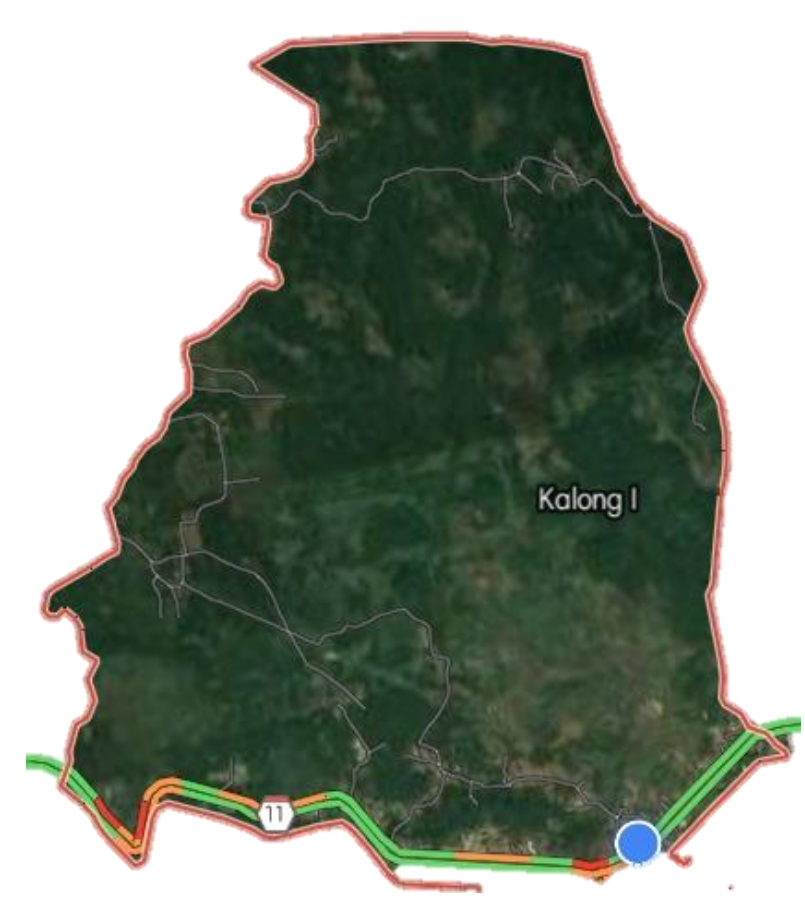

Batas Wilayah

\begin{tabular}{|c|l|l|}
\hline NO. & \multicolumn{1}{|c}{ Arah } & \multicolumn{1}{c}{ Berbatasan } \\
\hline 1. & Utara & Parung Panjang \\
\hline 2. & Selatan & Babakan Sadeng \\
\hline 3. & Barat & Cigudeg \\
\hline 4. & Timur & Kalong II \\
\hline
\end{tabular}

\section{Topografi Desa}

Desa Kalong I merupakan daerah dengan potensi mata air sedang.Sumber air bersih Desa Kalong I bersumber dari sumur galian dengan jumlah 1000 unit sumur untuk dimanfaatkan oleh 1397 KK. Kualitas air minum di Desa Kalong I pun terbilang baik, dengan rincian tidak berwarna juga tidak berbau.

\section{Demografi}

Desa Kalong I merupakan desa dengan jumlah kepadatan penduduk 1638,42 per KM. Terdiri atas 2940 penduduk laki-laki dan 2706 penduduk perempuan. Dengan jumlah total penduduk 5646 orang, $16 \%$ darinya adalah penduduk sedang sekolah, 2\% darinya adalah 
penduduk sedang TK/playgroup, 16,5\% darinya adalah penduduk belum TK/playgroup, dan sisanya adalah penduduk yang sudah tidak lagi sekolah.

Penduduk Desa Kalong I merupakan penduduk dengan beragam jenis pekerjaan. Diantara mata pencaharian tersebut adalah buruh tani sebanyak 46 orang, pegawai negeri sipil sebanyak 16 orang, pedagang barang kelontong sebanyak 339, guru swasta sebanyak 19 orang, pedagang keliling sebanyak 11 orang, karyawan perusahaan swasta sebanyak 62 orang, karyawan perusahaan pemerinta sebanyak 2 orang, pelajar sebanyak 155 orang, ibu rumah tangga sebanyak 1397 orang, perangkat desa sebanyak 8 orang, dan jasa penyewaan peralatan desa sebanyak 2 orang. Jenis pekerjaan ini merupakan beberapa sumber mata pencaharian dari penduduk Desa Kalong I.

Desa Kalong I merupakan desa dengan etnis sunda sebesar $100 \%$. Nilai ini membuktikan bahwa seluruh warga desa merupakan masyarakat yang kental dengan darah sunda. Bahasa keseharian yang digunakan masyarakat Desa Kalong I pun merupakan bahasa sunda. Hanya ada bebrapa warga yang mahir berbahasa Indonesia. Sisanya, tidak begitu mahir melakukan komunikasi menggunakan bahasa selain bahasa sunda.

\section{METODE PENGABDIAN}

\section{Tahapan Pelaksanaan}

Tahapan pelaksanaan untuk kegiatan ini sebagaimana terlihat pada bagan sebagai berikut:

\begin{tabular}{|c|c|c|c|c|c|c|c|c|c|c|c|c|c|c|c|c|c|c|c|c|c|c|c|c|c|c|c|c|c|c|c|c|}
\hline \multirow{2}{*}{ No. } & \multirow{2}{*}{ KEGLATAN } & \multicolumn{26}{|c|}{ AGUSTUS } & \multicolumn{5}{|c|}{ SEPTEMBER } \\
\hline & & 6 & 7 & 8 & 9 & 10 & 11 & 12 & 13 & 14 & 15 & 16 & 17 & 18 & 19 & 20 & 21 & 22 & 23 & 24 & 25 & 26 & 27 & 28 & 29 & 30 & 31 & 1 & \begin{tabular}{|l|}
2 \\
\end{tabular} & 3 & 4 & 5 \\
\hline 1 & Serah Terima Kecamatan Desa & & & & & & & & & & & & & & & & & & & & & & & & & & & & & & & \\
\hline 2 & Penerimaan di Desa Kalong 1 & & & & & & & & & & & & & & & & & & & & & & & & & & & 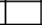 & & & & 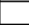 \\
\hline 3 & \begin{tabular}{|l} 
Silaturahmi dan Koordinasi dengan: \\
\end{tabular} & & & & & & & & & & & & & & & & & & & & & & & & & & & - & & & & \\
\hline & - DKM & & & & & & & & & & & & & & & & & & & & & & & & & & & 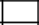 & 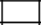 & 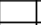 & 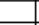 & 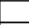 \\
\hline & - Karang Taruna dan Pemuda & & & & & & & & & & & & & & & & & & & & & & & & & & & 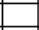 & & & & \\
\hline & - Paud dan Majlis Ta'lim & & & & & & & & & & & & & & & & & & & & & & & & & & & 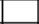 & 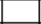 & & & 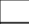 \\
\hline & - Ust. Ocang & & & & & & & & & & & & & & & & & & & & & & & & & & & 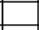 & & & & 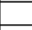 \\
\hline & - Ust. Ending & & & & & & & & & & & & & & & & & & & & & & & & & & & 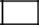 & & & & \\
\hline 4 & Silaturahmi dan Koordinasi dengan: & & & & & & & & & & & & & & & & & & & & & & & & & & & Z & - & - & _ & $\square$ \\
\hline & • Ust. Jaja & & & & & & & & & & & & & & & & & & & & & & & & & & & - & 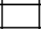 & 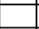 & & . \\
\hline & - Ust. Supriatna & & & & & & & & & & & & & & & & & & & & & & & & & & & 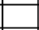 & - & 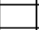 & & 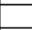 \\
\hline & - RW01 dan RW02 & & & & & & & & & & & & & & & & & & & & & & & & & & & - & & & & 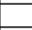 \\
\hline & \begin{tabular}{|l|l|} 
& Bpk. Deden \\
\end{tabular} & & & & & & & & & & & & & & & & & & & & & & & & & & & 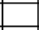 & & & & \\
\hline 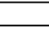 & - RT 05 dan RT 09 & & & & & & & & & & & & & & & & & & & & & & & & & & & ב & & 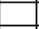 & & \\
\hline & - Kantor Desa & & & & & & & & & & & & & & & & & & & & & & & & & & & 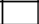 & 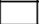 & 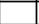 & & \\
\hline & Program & & & & & & & & & & & & & & & & & & & & & & & & & & & 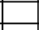 & 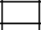 & - & - & \\
\hline & - Sosialisas Program Kerja & & & & & & & & & & & & & & & & & & & & & & & & & & & 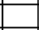 & & & & \\
\hline 6 & Bertemu dengan Sekdes & & & & & & & & & & & & & & & & & & & & & & & & & & & 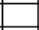 & & 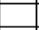 & & \\
\hline 7 & Lokakarya & & & & & & & & & & & & & & & & & & & & & & & & & & & 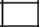 & & 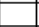 & & \\
\hline 8 & \begin{tabular}{|l|l|} 
Idul Adha \\
\end{tabular} & & & & & & & & & & & & & & & & & & & & & & & & & & & & & & & \\
\hline 9 & \begin{tabular}{|l|} 
Koordinasi Perangkat \\
Masyarakat Perancangan \\
17 Agustus 2019
\end{tabular} & & & & & & & & & & & & & & & & & & & & & & & & & & & & & & & \\
\hline 10 & \begin{tabular}{|l|} 
Observasi dan Pendirian \\
TEM (Taman Baca Masyarakat)
\end{tabular} & & & & & & & & & & & & & & & & & & & & & & & & & & & & & & & \\
\hline 11 & CAUSTUNG & & & & & & & & & & & & & & & & & & & & & & & & & & & & & & & \\
\hline 12 & \begin{tabular}{|l|} 
Quran Camp \\
\end{tabular} & & & & & & & & & & & & & & & & & & & & & & & & & & & & & & & \\
\hline 13 & 17 Agustus 2019 & & & & & & & & & & & & & & & & & & & & & & & & & & & & & & & \\
\hline 14 & Program English club & & & & & & & & & & & & & & & & & & & & & & & & & & & & & & & \\
\hline 15 & \begin{tabular}{|l|} 
Pernyuluhan Literasi Desa \\
\end{tabular} & & & & & & & & & & & & & & & & & & & & & & & & & & & & & & & \\
\hline 16 & $\begin{array}{l}\begin{array}{l}\text { Perryuluhan Cuci Tangan } \\
\text { Pakai Sabun }\end{array} \\
\end{array}$ & & & & & & & & & & & & & & & & & & & & & & & & & & & & & & & \\
\hline 17 & \begin{tabular}{|l} 
Pemeriksaan Kesehatan Gratis \\
\end{tabular} & & & & & & & & & & & & & & & & & & & & & & & & & & & & & & & \\
\hline 18 & \begin{tabular}{|l} 
Pernyuluhan Ekonomi \\
\end{tabular} & & & & & & & & & & & & & & & & & & & & & & & & & & & & & & & \\
\hline 19 & \begin{tabular}{|l|} 
Penerangan Jalan Umum \\
\end{tabular} & & & & & & & & & & & & & & & & & & & & & & & & & & & & & & & \\
\hline 20 & Fogging & & & & & & & & & & & & & & & & & & & & & & & & & & & & & & & 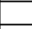 \\
\hline 21 & \begin{tabular}{|l} 
Pengajian Rutin \\
\end{tabular} & & & & & & & & & & & & & & & & & & 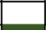 & & 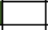 & & & & & & & & & & & \\
\hline 22 & \begin{tabular}{|l} 
Jumat Bersih dan Kerja Bakti \\
\end{tabular} & & & & & & & & & & & & & & & & & & & & & & & & & & & & & & 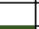 & \\
\hline 23 & Pawai obor & & & & & & & & & & & & & & & & & & & & & & & & & & & & & \begin{tabular}{|c} 
\\
\end{tabular} & & 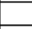 \\
\hline 24 & \begin{tabular}{|l|} 
Festival Anak Sholeh \\
\end{tabular} & & & & & & & & & & & & & & & & & & & & & & & & & & & & & & & $L$ \\
\hline 25 & \begin{tabular}{|l} 
Penutupan \\
\end{tabular} & & & & & & & & & & & & & & & & & & & & & & & & & & & 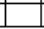 & & 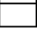 & & \\
\hline
\end{tabular}




\section{Metode Pendekatan}

Pendekatan yang digunakan dalam kegiatan ini dalam KKN ini yaitu dengan pendekatan sosial. Pendekatan sosial merupakan hal yang amat penting untuk dilakukan guna menunjang keberhasilan KKN. Oleh karena itu, penyelenggaraan KKN perlu didasari oleh pendekatan sosial yang tepat dan memadai, baik pada saat perencanaan, pelaksanaan, maupun pada tahap evaluasi.

Pendekatan sosial dilakukan melalui tahapan-tahapan yang sistematis, meliputi tahapan:

\section{Pembukaan Hubungan}

Dalam tahapan ini mahasiswa beserta dosen pembimbing dapat mengadakan diskusi atau lokakarya dengan semua pihak strategis di masyarakat tentang rencana kerja.

2. Pemeliharaan Hubungan

Hubungan yang telah terjalin melalui tahapan sebelumnya, selanjutnya perlu dipelihara dan dijaga agar suasana KKN tetap berjalan kondusif. Dalam pemeliharaan hubungan, komunikasi informal dapat memberikan hasil yang jauh lebih efektif.

\section{Pembinaan Hubungan}

Pembinaan hubungan terutama dilaksanakan oleh pengelola $\mathrm{KKN}$ (lembaga atau tim yang ditunjuk oleh perguruan tinggi yang bersangkutan) pada saat mengadakan pemantauan (monitoring) dan evaluasi terhadap rencana dan pelaksanaan kegiatan yang telah disetujui pihak-pihak strategis. Pada tahap ini dapat terjalin hubungan kerja sama antara Perguruan Tinggi dengan masyarakat yang tidak hanya sebatas KKN.

\section{Mengakhiri Hubungan}

Pada tahap ini peserta KKN berpamitan dengan masyarakat, baik secara formal maupun personal. Secara formal biasanya dilakukan secara seremonial dalam bentuk acara khusus pelepasan peserta KKN oleh masyarakat setempat.

\section{Partisipasi Masyarakat dalam Pelaksanaan Program}

Partisipasi masyarakat yang dapat dilakukan dalam kegiatan ini adalah sebagai berikut:

1. Menyediakan tempat tinggal bagi peserta KKN

2. Mempersiapkan tempat untuk pembinaan dan pelatihan.

3. Masyarakat bersama peserta $\mathrm{KKN}$ membangun infrastruktur

4. Pelaksanaan pengajian rutinan bersama peserta KKN

\section{Langkah Evaluasi}

Bentuk evaluasi yang dapat dirumuskan yaitu dinamai evaluasi proses; yang terkait dengan perencanaan, pelaksanaan dan monitoring kegiatan. Evaluasi proses akan dilakukan setiap pekan bersama dengan masyarakat.

Di antara evaluasi yang dilakukan terdiri dari:

1. Bidang Keagamaan

Pelaksanaan

kegiatan

Keagamaan dari masing-masing mahasiswa KKN 37 dan 38 Universitas Ibn Khaldun mendapatkan respon yang positif dari masyarakat sekitar, karena mahasiswa membantu masyarakat dalam peningkatan ilmu keagamaan dengan cara mengajarkan beberapa ilmu agama di kediaman salah satu ustad di RW 03 Desa Kalong I dan turut serta meramaikan pengajian rutin yang ada.

2. Bidang Ekonomi

Pelaksanaan kegiatan Ekonomi dari masing-masing mahasiswa KKN 37 dan 38 Universitas Ibn Khaldun 
mendapatkan respon yang positif dari masyarakat sekitar. Karena dalam programnya mahasiswa mengadakan penyuluhan ekonomi mengenai riba dan bahayanya serta mengajak anak-anak kecil di RW 03

Desa Kalong I untuk belajar menabung sejak dini dengan cara membuat kreasi menghias celengan.

3. Bidang Kesehatan

Pelaksanaan kegiatan

Kesehatan dari masing-masing mahasiswa KKN 37 dan 38 mendapatkan respon yang positif dari masyarakat sekitar. Dengan adanya kegiatan kesehatan dari mahasiswa KKN 2 Universitas Ibn Khaldun warga merasa senang mendapatkan himbauan kepada masyarakat untuk pola hidup bersih dan sehat. Mahasiswa memberikan penyuluhan dan praktik cuci tangan pakai sabun yang baik dan benar pada anak-anak di RW 03 Desa Kalong I dan mengadakan cek kesehatan gratis untuk LANSIA.
4. Bidang Pendidikan

Pelaksanaan kegiatan

Pendidikan dari masing-masing mahasiswa KKN 37 dan 38 mendapatkan respon yang positif dari masyarakat sekitar. Dengan adanya kegiatan pendidikan dari mahasiswa KKN 2 Universitas Ibn Khaldun warga merasa mendapatkan wawasan baru baik dari segi CALISTUNG, pembelajaran bahasa Inggris, dan keagamaan.

5. Bidang Teknologi dan Informasi

Pelaksanaan kegiatan di bidang teknologi ini adalah pembuatan penerangan jalan umum dengan jumlah 5 buah yang ditempatkan di titik-titik sisi jalan besar yang umumnya dilalui oleh banyak kendaraan. Pembuatan PJU ini mendapat respon positif dari masyarakat sekitar. Dengan memanfaatkan terik matahari pada siang hari, jenis lampu dengan sumber tenaga dari matahari ini akan menyala di malam hari. 


\section{REALISASI PROGRAM}

Berikut adalah capaian program yang telah dilaksanakan:

Bidang Pendidikan
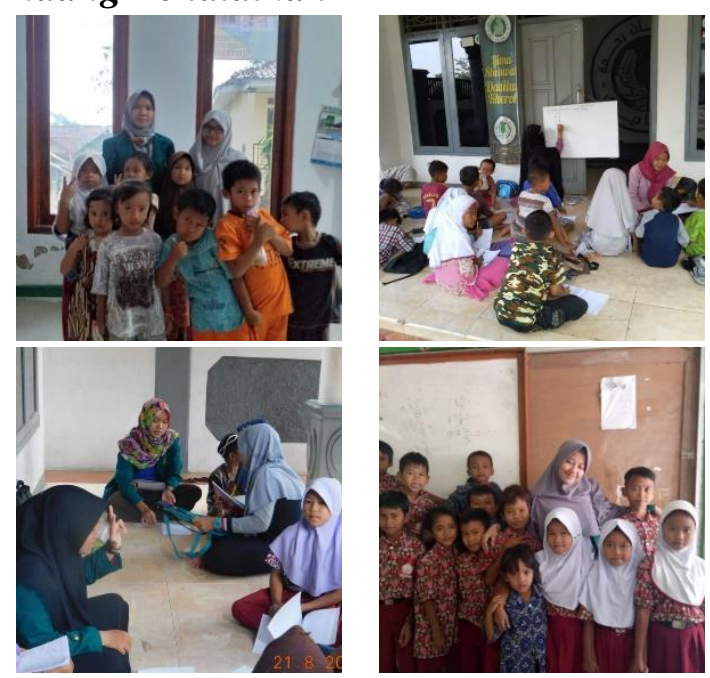

\section{a. CALISTUNG}

Sasaran kegiatan ini adalah anak-anak SD. Dilaksanakan pukul 13.00 s/d 15.00 WIB bertempat di Kediaman Ustad Ocang. Kegiatan ini diantaranya adalah membantu anak-anak belajar baca, tulis dan hitung, membantu anak-anak mengerjakan PR dari sekolahnya, dan memotivasi mereka agar semangat belajar

\section{b. English Club}

Sasaran kegiatan ini ditujukan kepada anakanak kelas III SD hingga SMP. Dilaksanakan setiap hari Selasa, Sabtu, dan Minggu pukul 13.00 s/d 15.00 WIB. Materi yang diajarkan adalah mengajarkan cara memperkenalkan diri dalam bahasa Inggris, nama-nama buah dan hewan.

\section{c. Revitalisasi Taman Baca Masyarakat}

Fungsi taman baca sebagai tempat belajar dan mencari informasi yang dibutuhkan masyarakat baik mengenai masalah yang langsung berhubungan dengan masalah pendidikan maupun bukan pendidikan. Program ini adalah upaya kami untuk revitalisasi taman baca yang sudah ada sebelumnya.

\section{Bidang Ekonomi}

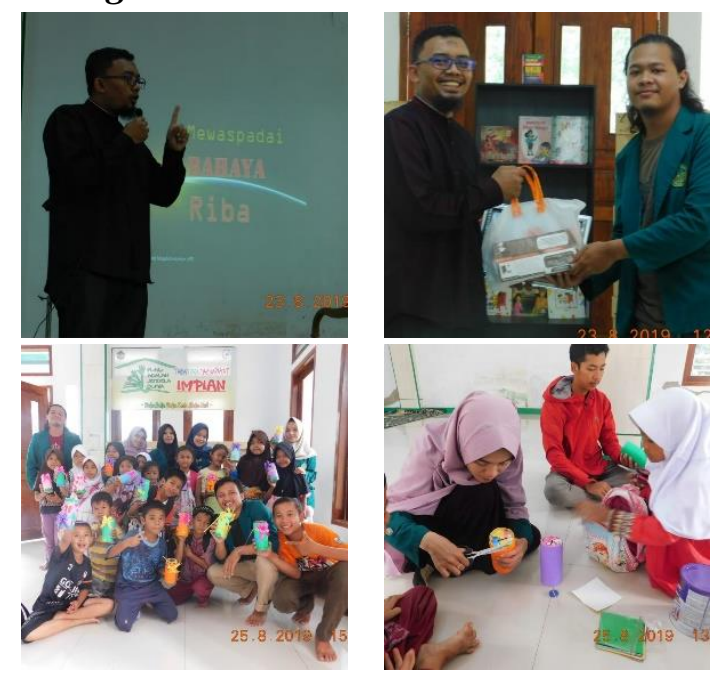

a. Penyuluhan Ekonomi mengenai Riba

Riba merupakan salah satu hal yang diharamkan oleh agama. Kegiatan penyuluhan ini dilakukan untuk memberikan wawasan kepada masyarakat Kampung Pabuaran Tonggoh agar menghindari riba. Pada kegiatan ini juga dibahas mengenai bagaimana masyarakat seharusnya dapat mengatur keuangannya, cara berniaganya, dan memanfaatkan keuangan dengan baik dan benar.

\section{b. Penyuluhan Menabung sejak Dini (Celengan Kreasi)}

Menabung merupakan salah satu langkah sederhana supaya kita dapat menyisihkan sebagian dana dari penghasilan untuk disimpan. Dengan menghias celengan juga dapat membuat daya pikat bagi anak-anak agar menabung lebih giat. 


\section{Bidang Keagamaan}
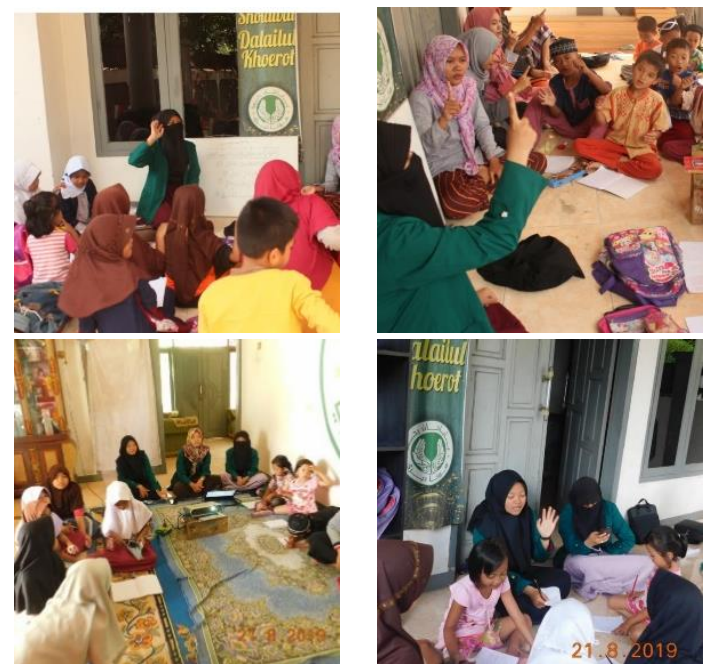

\section{a. Quran Camp}

Kegiatan Qur'an Camp ini dilaksanakan sebanyak 2-3 kali dalam seminggu. Kegiatan ini dimulai pukul 13.00-15.00 bertempat di Kediaman Ustad Ocang. Pada kegiatan ini, mahasiswa membantu anakanak untuk memiliki pengetahuan keagamaan sejak usia dini. Selain itu pelaksanaa Qur'an Camp ini juga bertujuan untuk memotivasi anak-anak untuk mampu mengaji, mengetahui sejarah Islam, dan berbahasa Arab agar mendapatkan bekal dunia dan akhirat.

\section{Bidang Kesehatan}
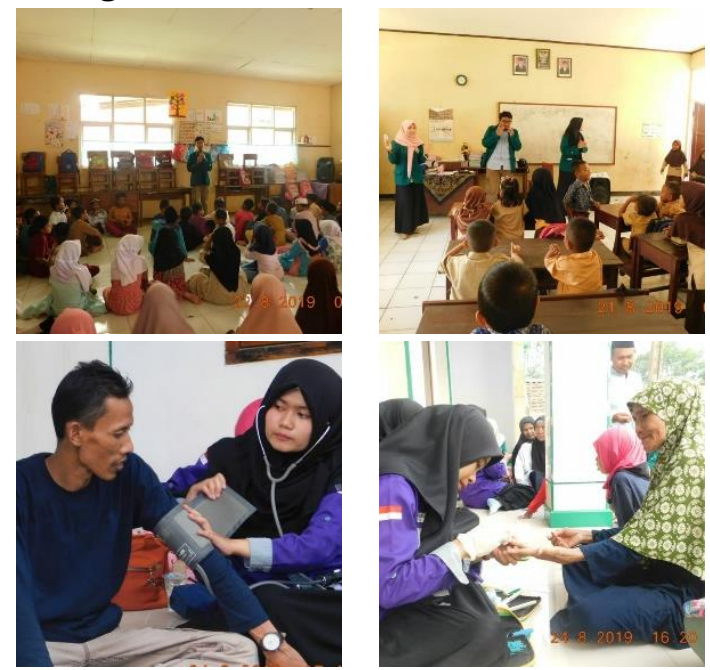

\section{a. Penyuluhan CTPS}

Penyuluhan cuci tangan pakai sabun ini merupakan salah satu cara sederhana dalam upaya peningkatan kesehatan masyarakat yang ada di desa ini yang dapat menimbulkan kesadaran pada anak-anak tentang hal-hal kecil yang dapat berpengaruh terhadap kesehatan mereka.

\section{b. Cek Kesehatan}

Kegiatan ini memiliki sasaran LANSIA dengan tujuan untuk membantu masyarakat RW 03 Desa Kalong 1 untuk mengetahui kualitas kesehatannya. Dilakukan pada hari Minggu tanggal 25 Agustus 2019.

\section{Bidang Teknologi dan Informasi}
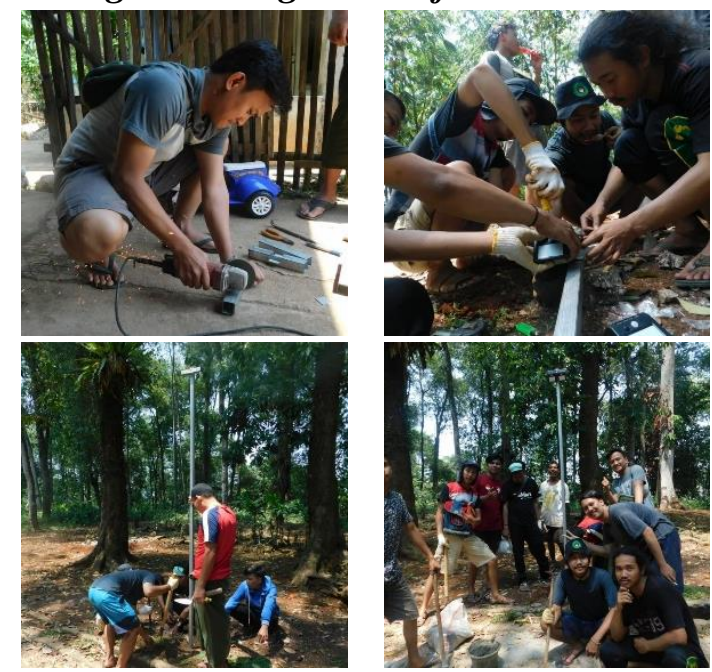

\section{a. Penerangan Jalan Umum}

Penerangan jalan umum adalah lampu yang digunakan untuk penerangan jalan di malam hari sehingga mempermudah pejalan kaki. Meningkatkan keselamatan lalu lintas dan keamanan dari para pengguna jalan. 


\section{KESIMPULAN}

Kuliah kerja nyata merupakan salah satu kegiatan untuk syarat wisuda setiap mahasiswa di Universitas Ibn Khaldun Bogor. Selama kurang lebih 30 hari, mahasiswa melakukan pendekatan dengan masyarakat dan merencakan programprogram kerja.

Desa Kalong I memiliki potensi yang banyak, terutama di bidang Pendidikan. Namun, fasilitasnya belum memadai sehingga masyarakat masih memiliki kesulitan dalam mengembangkan pendidikannya.

Maka peran mahasiswa dalam masyarakat ini adalah menjalankan program kerja yang sesuai untuk meningkatkan potensi Desa Kalong I.

Berdasarkan uraian program yang dipaparkan pada bab sebelumnya selama

\section{SARAN}

Berikut beberapa saran dan rekomendasi yang dapat kami jabarkan selama program KKN yang berlangsung di Desa Kalong I kecamatan Leuwisadeng:

1. Partisipasi masyarakat setempat untuk ikut serta menjaga dan melanjutkan program-program yang telah dijalankan kegiatan KKN di Desa Kalong I Kecamatan Leuwisadeng Kabupaten Bogor, berikut kami paparkan beberapa kesimpulan yang kami peroleh:

1. Terealisasinya program-program kerja KKN 2019 Universitas Ibnu Khaldun sebagai upaya pengabdian kepada masyarakat di desa Kalong I kecamatan Leuwisadeng kabupaten Bogor.

2. Terbentuknya jiwa sosisalisasi yang baik antara para mahasiswa yang mengikuti program $\mathrm{KKN}$ dengan warga setempat.

3. Meningkatnya rasa empati mahasiswa peserta KKN sehingga menumbuhkan rasa kepedulian dan kepekaan tinggi terhadap permasalahan yang dihadapi warga desa.

mahasiswa.

2. Pemberian dukungan penuh dalam bentuk moral maupun moril dari warga desa setempat.

Keikutsertaan seluruh apparat desa untuk bekerja sama dalam upaya peningkatan mutu dan kualitas desa. 


\section{REFERENSI}

Hidayatun, Annisa. Et.al (2019). Manajemen pembelajaran program kursus bahasa inggris di lembaga pendidikan bahasa inggris build better communications semarang. Artikel UNS 2019

Santoso, H. (2008). Membangun minat baca anak usia dini melalui penyediaan buku bergambar. Artikel Pustakawan Perpustakaan UM tahun 2011, 1.

Sutejo, R. Et.al (2019). pelaksanaan pembelajaran pada program diniyah untuk anak usia sekolah dasar di Desa Permata Baru Indrayana Utara Kabupaten Ogan Ilir.

Yana, Lola Fitri. Et.al (2019). Kebiasaan hidup bersih dan sehat pada anak usia dini di Kampung 1 Desa Muara Beliti Baru Kabupaten Musi Rawas.

Wulandari, Cahyo. Et.al (2019). Upaya peningkatan status kesehatan kelompok rentan dengan pendekatan pembelajaran dan pemberdayaan masyarakat. jurnal pengabdian masyarakat $2019 \mathrm{v} 01.5$ hal 167-187. 